\title{
Monitoring Arctic Environmental Changes Through the Application of the Next Generation Coupled Regional Climate Model
}

\author{
Farshid Daryabor*, Christian J Bjerrum \\ Department of Geosciences and Natural Resource Management, University of Copenhagen, Copenhagen, Denmark
}

Received: : March 19, 2018; Published: 眥 March 23, 2018

*Corresponding author: Farshid Daryabor, Department of Geosciences and Natural Resource Management, University of Copenhagen, Copenhagen, Denmark

Abbreviations: ROMS: Regional Ocean Modeling System; WRF: Weather Research and Forecasting; EVP: Elastic-Viscous-Plastic

\section{Introduction}

Global warming is associated with significant polar amplification feedbacks. But how strong is the amplification? Will it be a slow increase or will it accelerate in the coming 20-100 years? This is currently unknown, despite 20 years of research. One of the problems is that most Arctic processes feedbacks reside in the eddy resolving detail because of the high latitude nature of the problem with a small Rossby Radious of deformation. As a result, a high-resolution model is needed to capture eddy-resolution at high latitude zones. The Arctic cloud-radiation feedback when coupled with the ice-albedo feedback is not adequately captured in the current coupled climate models [1], partly due to the coarse resolutions of both the atmosphere and ocean models that will fundamentally affect quantification of polar amplification. The proposed model framework will permit a new transformative way of thinking about the climate feedbacks (ocean-atmosphere exchange) in the Arctic both positive and negative. Changes to the marine biota are known to involve oceanic oxygen and carbonate chemistry. This understanding is very essential to mitigate the impacts, thus reducing the risks towards the survival and adaptation of the oceanic ecosystems and fisheries in the Arctic and its surrounding areas. However, considerable uncertainty in the projections of future climate change has led to the uncertainty in the projection of oxygen and carbonate chemistry. Increase of the air temperatures up to $\sim 1.5 \mathrm{oC}$, due to global warming is enough to thaw permafrost in the Arctic faster than ever. This in itself can cause nutrients that have been trapped for thousands of years to be flushed into the Arctic surface ocean much faster than ever before. Hence, this research project will attempt to address how these potential additional nutrient fluxes may affect the Arctic region. In view of the above, implementing a super-regional Arctic high-resolution coupled climate-biogeochemical cycle model is fundamental to resolve uncertainties in Arctic climate change not only in the projection of future climate change but also the consequent projection of ocean acidification which can impact lower latitude areas too. Thus, the new coupled model which incorporates the coupling of oceanatmosphere-sea ice-wave-biogeochemical- sediment transport is proposed, [1] to demonstrate more accurately the changes in ocean oxygen and carbonate chemistry based on the future climate change projections and [2] to enhance the level of understanding on how the melting of permafrost, gas-hydrates and the Greenland ice sheet contributes to the release of additional amounts of nutrients into the Arctic Ocean. This project will also enable further probing of the changes in anoxia and organic matters that have yet to be investigated sufficiently in the changing climate.

The importance of the research study is to address both basic and novel questions at various spatiotemporal scales due to complexity of the biogeochemical cycle and trace gases in response to the climate change and the consequent ocean-atmosphere interaction that affects future ecosystems. During the year 2016 the average surface temperature over the Arctic land had reached $2.0{ }^{\circ} \mathrm{C}$ as compared to the period 1981-2010 [2] (Figure 1a), representing an increase of surface temperature approximately of $3.5^{\circ} \mathrm{C}$ since 1900 . Time series of the mean sea-surface temperature anomaly over the Arctic Ocean (i.e., Chukchi Sea, East Baffin Bay and Barents Sea) shows a significant warming trend at a rate of about $+0.5^{\circ} \mathrm{C}$ decade-1 since 1982 (Figure 1b). This in itself indicate that the rapid decrease in the thickness of the Arctic sea ice would happen in the next few decades if global warming 
continues. Future changes in the Arctic and Greenland ice sheet mass, particularly due to changes in ice flow, are a major source of uncertainty that can increase the associated risks to the ecosystem, a melting of near coastal permafrost. Projections of climate change and its impacts beyond about 2050 are currently strongly scenarioand model-dependent. Thus, improved projections would require improved models with coupling of ocean-atmosphere-sea icewave-biogeochemical- sediment transport as study here.

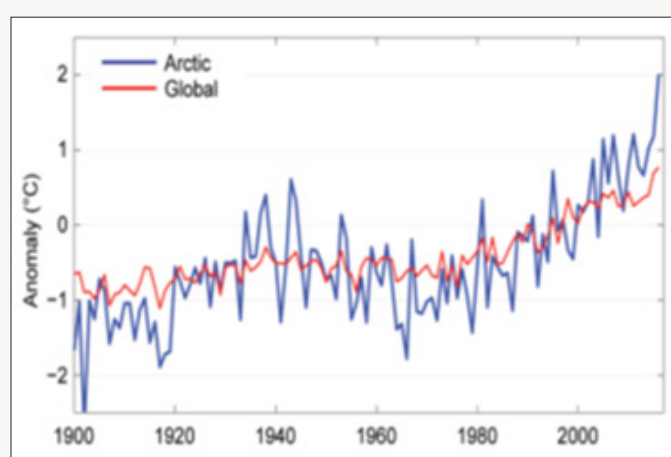

a)

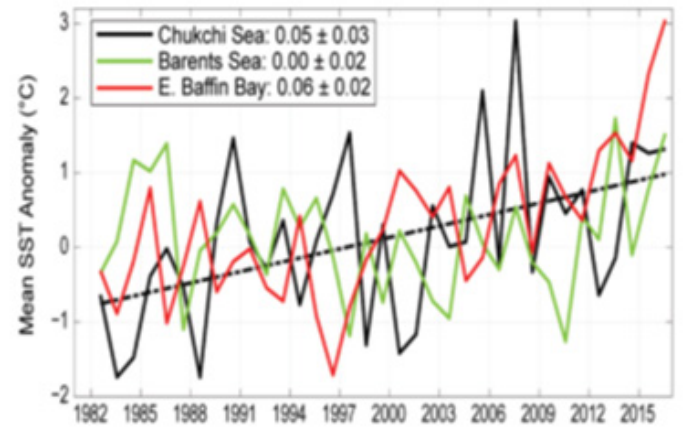

b)

Figure 1: (a) Arctic and global average annual land surface air temperature anomalies $\left({ }^{\circ} \mathrm{C}\right)$ for $1900-2016$ relative to the 19812010 average, (b) Time series of the area-averaged SST anomalies $\left({ }^{\circ} \mathrm{C}\right)$ average for the August over the period $1982-2010$ in the Arctic Ocean. The dash-dotted black line in (b) shows the linear SST trend over the corresponding period. Numbers in the legend correspond to linear trends in ${ }^{\circ} \mathrm{C}$ year-1 (with 95\% confidence intervals) (from Blunden et al. [2]). Note that the increasing trend in temperature coincides with the declining trend in mass of the Greenland ice sheet (as shown in the figure 1. Blunden et al. [2]).

The following approach: a high-resolution coupled oceanatmosphere-sea ice-wave-biogeochemical- sediment transport model that simulates atmosphere, ecosystem and ocean climate. The ocean model is the Regional Ocean Modeling System (ROMS) in the coupled system is a split-explicit free-surface model based on the Boussinesq and hydrostatic approximations that solve incompressible primitive equations [3]. Dispersion errors are reduced by using a third-order upstream-biased, dissipative advection scheme, which enhances the grid resolution accuracy. The split of advection and diffusion resolves spurious diapycnal mixing in the sigma coordinates. The mixing can be attributed to the implementation of higher order diffusive advection schemes. The method used in this simulation retains the low dispersion and diffusivity capabilities of the original scheme. The atmospheric model component in the coupled system is the Advanced Research Weather Research and Forecasting (WRF) Model [4]. It is a nonhydrostatic, quasi-compressible atmospheric model with boundary layer physics schemes and a variety of physical parameterizations of sub-grid scale processes for predicting meso- and micro-scales of motion and cloud formation. The seaice component in the coupled system currently integrated into the ROMS model that is a combination of the elastic-viscousplastic (EVP) rheology and simple one-layer ice and snow thermodynamics with a molecular sublayer under the ice. The wave model is combination of SWAN and MASNUM. SWAN is a spectral wave model specifically designed for shallow water that solves the spectral density evolution equation [5]. SWAN simulates wind wave generation and propagation in coastal waters and includes the processes of refraction, diffraction, shoaling, wave-wave interactions, and dissipation due to whitecapping, wave breaking, and bottom friction.
MASNUM wave number spectral model, a third generation wave model, developed by the Laboratory of Geophysical Fluid Dynamics (First Institute of Oceanography, State Oceanic Administration of China). The MASNUM coupled to ROMS in order to evaluate the wave-induced mixing in the upper ocean and the impact of surface waves on ocean-atmosphere fluxes and ecosystem dynamics. The model implemented in the coupled system for the computation nonbreaking wave-induced mixing parameter [6]. Biogeochemical ecosystem model based on the coupling of nitrate, ammonium, phosphate, and sulfur cycles [7]. The sediment-modeling component is from the Community Sediment Transport Modeling System. Currently these components are integrated into the ROMS model [8]. The sediment routines have been used to represent the simulate a variety of inner shelf and estuarine sediment processes. The coupler is the Model Coupling Toolkit [8] that allows the transmission and transformation of various distributed data between component models using a parallel-coupled approach.

\section{References}

1. Zhao M, Wang Z (2010) Comparison of Arctic clouds between European Center for Medium-Range Weather Forecasts simulations and Atmospheric Radiation Measurement Climate Research Facility longterm observations at the North Slope of Alaska Barrow site. J. Geophys. Res 115(D23202): 1-17.

2. Blunden J, DS Arndt (2017) State of the Climate in 2016. Blunden J, DS Arndt (Eds) Bull Amer Meteor Soc 98 (8): S1-S277.

3. Shchepetkin A, McWilliams JC (2005) The Regional Oceanic Modeling System (ROMS): a split-explicit, freesurface, topography-followingcoordinate oceanic model. Ocean Model 9(4): 347-404.

4. Skamarock WC, Klemp JB, Dudhia J, Gill DO, Barker DM, et al. (2005) A Description of the Advanced Research WRF Version 2. NCAR Technical Note, NCAR/TN-468+STR. 
5. Booij N, Ris RC, Holthuijsen LH (1999) A third-generation wave model for coastal regions. Part I: Model description and validation. J. Geophys. Res 104 (C4): 7649-7666.

6. Qiao F, Yuan Y, Yang Y, Zheng Q, Xia C, et al. (2004) Wave induced mixing in the upper ocean: Distribution and application to a global ocean circulation model. Geophys Res Lett 31(11): L11303.
7. Azhar MA, Canfield DE, Fennel K, Thamdrup B, Bjerrum CJ (2014) A model-based insight into the coupling of nitrogen and sulfur cycles in a coastal upwelling system. J Geophys Res 119(3): 264-285.

8. Warner JC, Brandy A, Ruoying H, Joseph BZ (2010) Development of a coupled ocean-atmosphere-wave-sediment transport (COAWST) modeling system. Ocean model 35(3): 230-244.

\section{(C) This work is licensed under Creative}

To Submit Your Article Click Here: Submit Article

DOI: $10.32474 /$ MAOPS.2018.01.000111

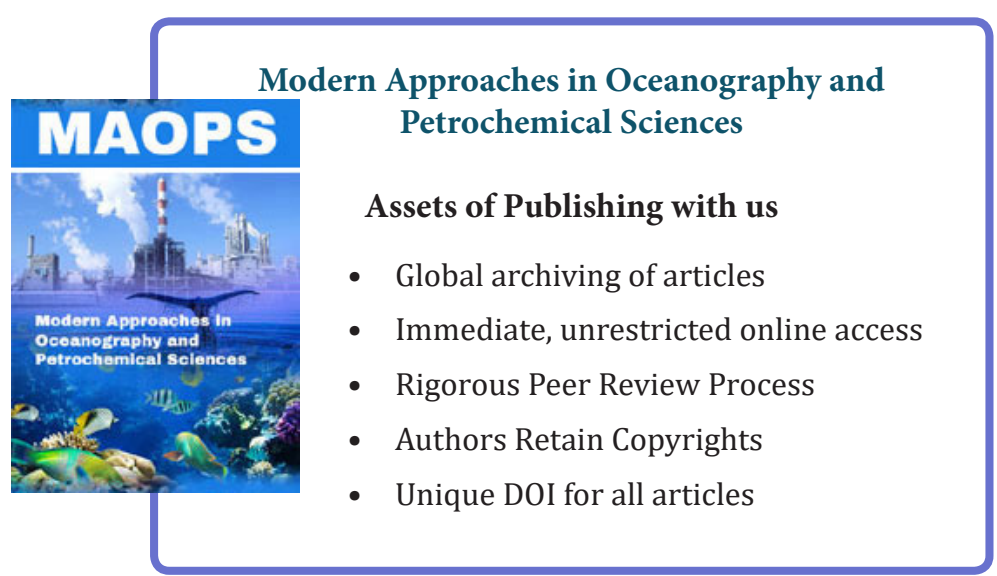

